\title{
Use of combined maximum and minimum intensity projections to determine internal target volume in 4-dimensional CT scans for hepatic malignancies
}

Jin Liu, Jia-Zhou Wang, Jian-Dong Zhao, Zhi-Yong Xu and Guo-Liang Jiang*

\begin{abstract}
Background: To evaluate the accuracy of the combined maximum and minimum intensity projection-based internal target volume (ITV) delineation in 4-dimensional (4D) CT scans for liver malignancies.

Methods: 4D CT with synchronized IV contrast data were acquired from 15 liver cancer patients (4 hepatocellular carcinomas; 11 hepatic metastases). We used five approaches to determine ITVs: (1). ITV Allphases: contouring gross tumor volume (GTV) on each of 10 respiratory phases of $4 D C T$ data set and combining these GTVs; (2). ITV 2 phase: contouring GTV on CT of the peak inhale phase (0\% phase) and the peak exhale phase (50\%) and then combining the two; (3). ITV MIP: contouring GTV on MIP with modifications based on physician's visual verification of contours in each respiratory phase; (4). ITV MinIP: contouring GTV on MinIP with modification by physician; (5). ITV $2 \mathrm{M}$ : combining ITV MIP and ITV MinIP. ITV AllPhases was taken as the reference ITV, and the metrics used for comparison were: matching index (MI), under- and over-estimated volume $\left(\mathrm{V}_{\text {under }}\right.$ and $\left.\mathrm{V}_{\text {over }}\right)$.

Results: 4D CT images were successfully acquired from 15 patients and tumor margins were clearly discernable in all patients. There were 9 cases of low density and 6, mixed on CT images. After comparisons of metrics, the tool of ITV $2 \mathrm{M}$ was the most appropriate to contour ITV for liver malignancies with the highest MI of $0.93 \pm 0.04$ and the lowest proportion of $\mathrm{V}_{\text {under }}(0.07 \pm 0.04)$. Moreover, tumor volume, target motion three-dimensionally and ratio of tumor vertical diameter over tumor motion magnitude in cranio-caudal direction did not significantly influence the values of $\mathrm{Ml}$ and proportion of $\mathrm{V}_{\text {under }}$.
\end{abstract}

Conclusion: The tool of ITV $2 \mathrm{M}$ is recommended as a reliable method for generating ITVs from 4D CT data sets in liver cancer.

Keywords: liver malignancy, radiotherapy, internal target volume, 4-dimensional $\mathrm{CT}$, maximum intensity projection, minimum intensity projection

\section{Introduction}

Primary and metastatic hepatic malignancies are commonly treated by surgery, but radiation therapy is also one of options as non-surgical modalities. It has been demonstrated that radiation therapy is feasible and the outcomes are promising $[1,2]$. However, due to respiration liver motion up to $3 \mathrm{~cm} \mathrm{[3]} \mathrm{is} \mathrm{one} \mathrm{of} \mathrm{obstacles} \mathrm{to}$ accurately localize the target. Moreover, respiratory-

\footnotetext{
* Correspondence: jiangg|47@hotmail.com

Department of Radiation Oncology, Fudan University Shanghai Cancer Center. 270 Dong An Road, Shanghai, 200032, China
}

induced tumor motion is known to be anisotropic, thus individual determination of internal margin around gross tumor volume (GTV) is crucial to form an internal target volume (ITV), which can avoid both inadequate tumor coverage and unnecessary liver parenchymal irradiation for individual patient. Fourdimensional computed tomography (4D CT) is one of appropriate approaches to estimate and determine ITV for tumor with respiratory motion $[4,5]$.

4D CT has been widely used in lung cancer to determine ITV [6,7]. Ideally, ITV should be delineated by 
manually contouring GTV in all 10 breath phases of a 4D scan image sets to form ITV, which is the most accurate tool to determine ITV, but it is a time-consuming and labor-intensive task. To reduce the workload of contouring multiple GTVs, one solution is to contour only two extreme phases at end-inhalation and endexhalation and then to sum of the two becoming ITV $[8,9]$; and the other is to use the post-processing tools of maximum intensity projection (MIP) and minimum intensity projection (MinIP) from 4D CT data sets to generate ITV. MIP-based ITV delineation is performed on a single 3-D CT data set, where each pixel in this set represents the brightest object encountered by corresponding voxels in all volumetric 4D CT data sets, for instance, MIP-based ITV delineation for lung cancer, which was recommended as a reliable tool and a good first estimation [10-12]. Conversely, MinIP-based ITV is on the CT set, where each pixel represents the lowest data value in the volumetric data [10].

MIP and MinIP methods seem not suitable for liver cancer because most tumors in the liver have similar attenuation to the normal liver parenchyma and therefore are not easily discernable. Contrast-enhanced CT scan has been routinely used for radiation oncologists to differentiate the tumor from normal tissues. It should be noted that regardless of with contrast enhancement or not, most liver tumors present inhomogeneous density, either because of the inherent nature of the tumor, such as the routes of blood supply, vascular volume and permeability, or because of areas of fluid, hemorrhage, and necrosis within tumors, or because of secondary change due to treatments, for example, iodine deposition as a result of transcatheter arterial chemoembolization (TACE). Recently, Beddar et al described a simple method for 4D CT acquisition by using synchronized intravenous contrast injection to improve the accuracy of liver tumor delineation. By this way most liver metastases and cholangiocarcinomas can be identified on image of portal venous phase, while HCC, most visible in the delayed phase [13].

In theory, for tumors with homogeneous hyperdensity or hypodensity comparing to the surrounding normal liver, MIP or MinIP projections should accordingly reflect the tumor trajectory across all time-resolved data sets. Visualization of tumor with mixed-density means the tumor border should be discernable; regardless which part of it is more hyperdense or hypodense than the adjacent liver parenchyma. Using MIP technique or MinIP technique only definitely misses the spatial information of the moving liver tumor. Therefore, our hypothesis is to combine MIP and MinIP, which may fit for the situation of mixed tumor density. Thus, the purpose of this study is to evaluate the feasibility and accuracy of the MIP and/or MinIP-based ITV delineation in 4DCT scans for liver tumors.

\section{Methods \\ Patient selection}

Patients who met the following criteria were qualified to this study: (1). Patient suffered from hepatic malignancies, primary or metastatic, and were planned to receive irradiation; (2). The margins of hepatic lesion were clear on intravenous contrast enhanced CT; (3). Patient's breath was regular after a training session; (4). Patient did not have the history of allege to contrast; and (5). Informed consent was obtained.

\section{D CT image acquisition}

In order to enhance the visibility of tumors on $4 \mathrm{D} \mathrm{CT}$, $100 \mathrm{~mL}$ of contrast at a concentration of $300 \mathrm{mg} \mathrm{I} / \mathrm{mL}$ was injected synchronously with 4D CT image acquisition. All patients were imaged during the portal venous phase. A time delay was programmed within 4D CT image acquisition protocol so that the start of contrast injection is initiated simultaneously with the start of the scanner's timer countdown. For those with liver metastases, the liver was scanned with a $45 \mathrm{~s}$ time delay, while for hepatocellular carcinoma (HCC) patients the time delay was $65 \mathrm{~s}$. This CT scan protocol was proposed by Beddar et al [13].

All patients were immobilized using customized vacuum lock in supine position with arms placed on their forehead. A16-slice Brilliance Big Bore CT scanner (Philips Co.) was used for 4D CT image acquisition. The patient respiration was tracked using Real-Time Position Management (RPM) System (Varian Medical Systems, Palo Alto, CA). The region of interest usually comprises the area from 2 to $3 \mathrm{~cm}$ above diaphragm to iliac crest. A 4D CT scan is performed in cine mode with at least one complete breath cycle for each couch position. After scanning 4-dimensional images were binned based on the respiratory traces to become a complete image set, which covered each of 10 breathing phases. MIP and minimum intensity projections (MinIP) were then generated from the raw data set of 4D CT scans.

\section{ITV determination}

All reconstructed CT series were transferred to MIM software (Version 5.1, MIMvista Corp., Cleveland, OH). Window/level was adjusted to optimize the visual contrast between the tumor and normal parenchyma regions. All the contours were drawn by a single radiation oncologist (JL) and verified by a senior radiation oncologist (JDZ). We used 5 approaches to determine

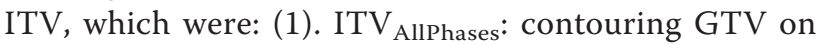
each of 10 respiratory phases of 4D CT data set and 

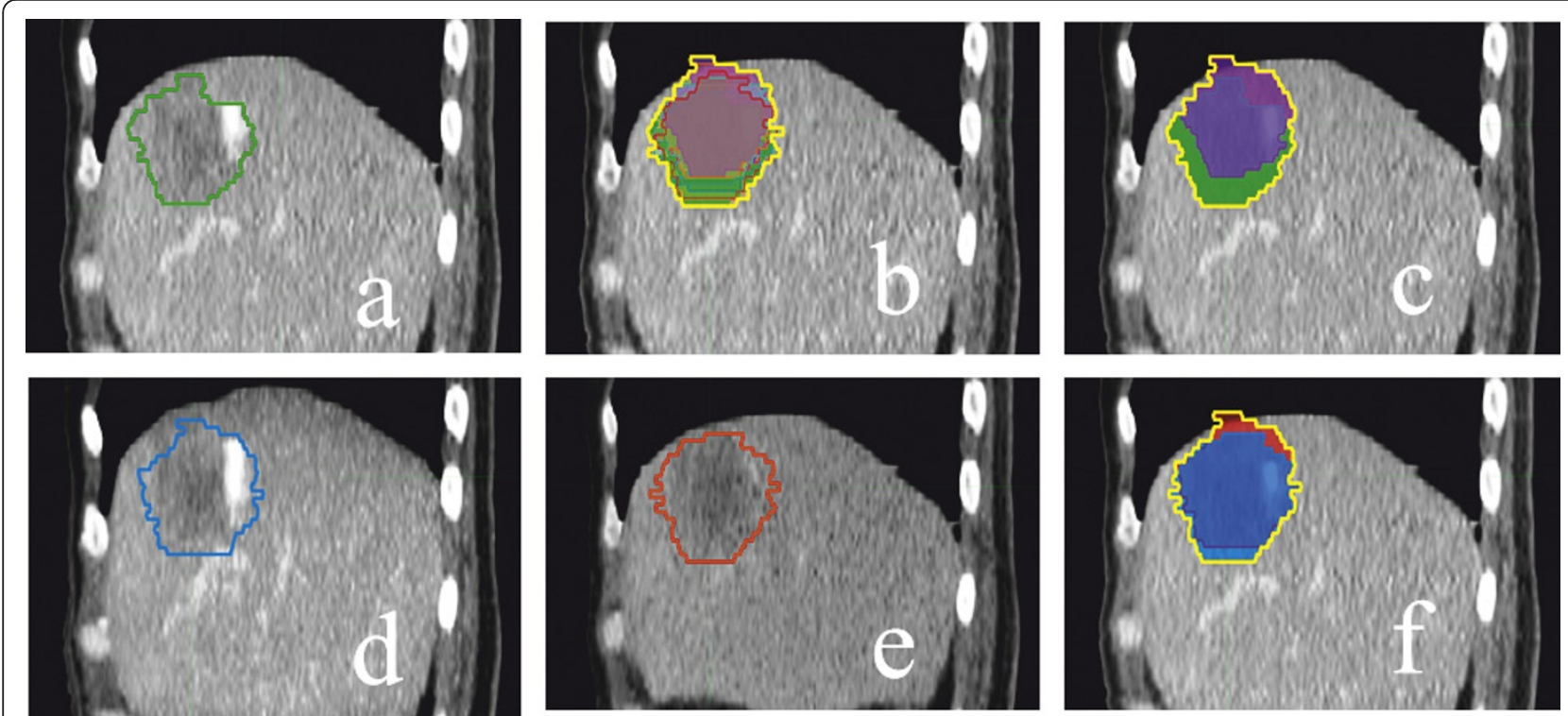

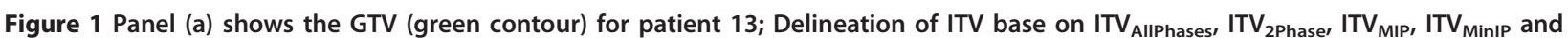
$\mathrm{ITV}_{2 \mathrm{M}}$ are shown in panels (b), (c), (d), (e) and (f), respectively. ITV MIP and ITV MinIP coutours are as they appear on the intensity projection data set; all others are registered to the $0 \%$ phase of the $4 \mathrm{D} C \mathrm{CT}$ data set.

combining these GTVs; (2). ITV 2 Phase: contouring GTV on CT of the peak inhale phase ( $0 \%$ phase) and the peak exhale phases $(50 \%)$ and then combining the two;

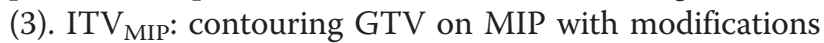
based on physician's visual verification of contours in

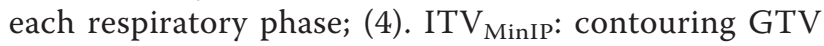
on MinIP with modification by physician; (5). ITV IM $_{2}$ :

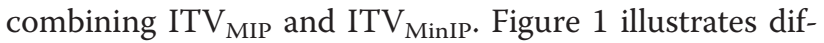
ferent approaches in the determination of ITV for patient 13.

\section{Evaluation of target motion}

We used MIM software (version 5.1) to measure craniocaudal, left-right and anterior-posterior movement of the tumor. Tumor motion was also expressed as a 3D vector, which is the quadratic mean of the motions in 3 orthogonal directions.

\section{Data analysis and statistics}

ITV $_{2 \text { Phase, }}$ ITV $_{\text {MIP }}$, ITV $V_{\text {MinIP }}$ and ITV $\mathrm{ITM}_{2 \mathrm{M}}$, as the tested ITVs, would be compared with the reference of ITV $\mathrm{All}_{\text {- }}$ Phases, respectively. The metrics used for comparison were: (1) Matching index (MI), which was the percentage of overlapped volume in 3-dimensions between 2 ITVs. When 2 ITVs were totally overlapped, MI was 1.00 , whereas when 2 ITVs were totally separate, MI was 0 ; and (2) under- and over-estimated volume $\left(\mathrm{V}_{\text {under }}\right.$ and $\left.\mathrm{V}_{\text {over }}\right)$. A tested ITV ( $\left.\mathrm{V}_{\text {test }}\right)$ was compared to the standard volume, ITV $V_{\text {AllPhases }}$. The formulas were: $V_{\text {under }}$ $=\mathrm{V}_{\text {AllPhases }} \backslash \mathrm{V}_{\text {test }}$, and $\mathrm{V}_{\text {over }}=\mathrm{V}_{\text {test }} \backslash \mathrm{V}_{\text {AllPhases }}$.

$$
\begin{aligned}
& \text { VUnder }=\int \text { Aallphase }(Z) \backslash \text { Atest }(Z) d z \\
& \text { VOver }=\int \operatorname{Atest}(Z) \backslash \text { Aallphase }(Z) d z
\end{aligned}
$$

The definitions and calculations of those metrics were referred to Ezhil [12].

Paired sample $t$-test and Independent-Samples $\mathrm{T}$ test (SPSS v.13, SPSS Inc., Chicago, IL) were applied to compare the differences with $p$ value of $<0.05$ considered significant.

\section{Results}

\section{Patients}

From August 2010 to February 2011, 15 eligible patients with liver cancer were enrolled in this study and underwent 4D CT simulation for irradiation treatment planning in our institution. Of these patients $11 \mathrm{had}$ metastatic liver cancers and 4, HCC with mean lesion volume of $152 \mathrm{~cm}^{3}$ (range, $2 \mathrm{~cm}^{3}-932 \mathrm{~cm}^{3}$ ). 4D CT images were successfully obtained from 15 patients and tumor margins were clearly discernable in all patients. There were 9 cases of low density and 6, mixed on CT images (Table 1).

\section{Target motion}

The cranio-caudal motion of the target was predominant with a mean distance of $8.0 \mathrm{~mm} \pm 3.3 \mathrm{~mm}$, while the left-right and anterior-posterior motions were much 
Table 1 Tumor Characteristics

\begin{tabular}{|c|c|c|c|c|c|}
\hline Patient & Tumor & Tumor size* $(\mathrm{mm})$ & $\operatorname{GTV}\left(\mathrm{cm}^{3}\right)$ & Location & Tumor density \\
\hline 1 & $\mathrm{HCC}$ & $51 \times 42 \times 23$ & 34 & Right upper lobe; adjacent to right lung. & Mixed \\
\hline 2 & LM from lung cancer & $33 \times 49 \times 33$ & 30 & Left lobe; intrahepatic & Low \\
\hline 3 & LM from gastric carcinoma & $42 \times 78 \times 52$ & 77 & Caudate and left lobe; intrahepatic & Low \\
\hline 4 & LM from pancreatic carcinoma & $42 \times 51 \times 48$ & 66 & Right lower lobe; intrahepatic & Mixed \\
\hline 5 & LM from nasopharyngeal carcinoma & $12 \times 15 \times 15$ & 2 & Right upper lobe; intrahepatic & Low \\
\hline 6 & LM from rectal carcinoma & $10 \times 12 \times 11$ & 2 & Right upper lobe; intrahepatic & Low \\
\hline 7 & $\mathrm{HCC}$ & $35 \times 39 \times 48$ & 59 & Right upper lobe; adjacent to right lung & Mixed \\
\hline 8 & LM from gallbladder carcinoma & $9 \times 18 \times 18$ & 3 & Right lower lobe; intrahepatic & Low \\
\hline 9 & LM from gastric carcinoma & $51 \times 99 \times 58$ & 213 & Left lobe; adjacent to stomach & Low \\
\hline 10 & $\mathrm{HCC}$ & $78 \times 96 \times 99$ & 384 & Right lobe; adjacent to right lung and kidney & Mixed \\
\hline 11 & LM from lung cancer & $50 \times 59 \times 45$ & 80 & Left lobe; adjacent to stomach & Low \\
\hline 12 & LM from gallbladder carcinoma & $33 \times 38 \times 42$ & 28 & Right lobe; intrahepatic & Low \\
\hline 13 & LM from rectal carcinoma & $54 \times 56 \times 54$ & 91 & Right upper lobe; adjacent to right lung & Mixed \\
\hline 14 & $\mathrm{HCC}$ & $108 \times 126 \times 145$ & 932 & Right upper lobe; adjacent to right lung & Mixed \\
\hline 15 & LM from esophageal carcinoma & $60 \times 91 \times 88$ & 284 & Right lobe; adjacent to right lung and kidney & Low \\
\hline
\end{tabular}

Abbreviations: GTV: gross tumor volume; HCC: hepatocellular carcinoma; LM: liver metastasis.

*Tumor size was expressed as multiplying diameters in cranio-caudal, in left-right and in anterior-posterior directions.

less with mean values of $1.6 \mathrm{~mm} \pm 0.9 \mathrm{~mm}$ and $3.2 \mathrm{~mm}$ $\pm 2.2 \mathrm{~mm}$, respectively (Table 2 ).

\section{Comparison of ITVs countered by different approaches (1). ITVs volume}

Table 3 shows all volumes of ITV. The mean volume of

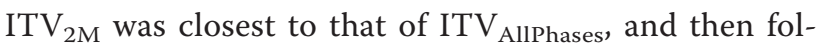
lowed by $\mathrm{ITV}_{2 \text { Phase. }}$ The volume difference between $\mathrm{ITV}_{2 \mathrm{M}}$ and $\mathrm{ITV}_{2 \text { Phase }}$ was statistically significant with a $p$ value of 0.04 . Taking ITV $_{\text {AllPhases }}$ as the reference, the mean ratios of the tested ITVs to ITV $\mathrm{Illlphases}_{\text {were }}$ $88.9 \% \pm 5.7 \%, 82.7 \% \pm 12.6 \%, 82.5 \% \pm 10.8 \%$ and $94.0 \%$

Table 2 Motion magnitudes of GTV centroid measured by 4D CT in 15 patients $(\mathrm{mm})$

\begin{tabular}{lllll}
\hline Patient & Cranio-caudal & Left-right & Anterior-posterior & 3D vector \\
\hline 1 & 8.8 & 2.9 & 2.3 & 9.6 \\
2 & 11.9 & 1.1 & 1.4 & 12.0 \\
3 & 6.9 & 1.0 & 2.8 & 7.5 \\
4 & 8.8 & 1.3 & 3.0 & 9.4 \\
5 & 8.7 & 1.7 & 2.2 & 9.1 \\
6 & 10.0 & 1.1 & 3.9 & 10.8 \\
7 & 15.2 & 2.5 & 8.1 & 17.4 \\
8 & 7.6 & 3.6 & 4.3 & 9.5 \\
9 & 8.0 & 1.1 & 1.4 & 8.2 \\
10 & 5.3 & 2.7 & 8.2 & 10.1 \\
11 & 3.4 & 1.0 & 3.2 & 4.8 \\
12 & 3.0 & 1.0 & 2.1 & 3.8 \\
13 & 11.5 & 1.7 & 2.3 & 11.9 \\
14 & 3.9 & 0.9 & 0.7 & 4.1 \\
15 & 7.4 & 1.0 & 1.7 & 7.7 \\
Mean & 8.0 & 1.6 & 3.2 & 9.1 \\
SD & 3.3 & 0.9 & 2.2 & 3.4 \\
\hline
\end{tabular}

$\pm 3.6 \%$, respectively for $\mathrm{ITV}_{2 \text { phase, }} \mathrm{ITV}_{\text {MinIP }}, \mathrm{ITV}_{\mathrm{MIP}}$ and $\mathrm{ITV}_{2 \mathrm{M}}$.

(2). MI

As shown in Table 4, ITV $2 \mathrm{M}$ was closest matched with $\mathrm{ITV}_{\text {AllPhases }}$ with mean MI of $0.93 \pm 0.04$, and mean MIs were $0.89 \pm 0.06,0.82 \pm 0.12$ and $0.82 \pm 0.10$, respectively for $\mathrm{ITV}_{2 \text { Phase }}$ ITV $\mathrm{IVinIP}_{\text {M }}$ and $\mathrm{ITV}_{\text {MIP. The differ- }}$ ences of MI were statistically significant between $\mathrm{ITV}_{2 \mathrm{M}}$ and $\operatorname{ITV}_{2 \text { Phase }}(p=0.004)$, between $\operatorname{ITV}_{2 M}$ and $\operatorname{ITV}_{\text {MinIP }}$ $(p=0.003)$, and between $\operatorname{ITV}_{2 M}$ and $\operatorname{ITV}_{\text {MIP }}(p=$ 0.000). All the other comparisons between ITVs were not significant.

Table 3 Volumes of ITV AllPhases, $_{\text {ITV }}$ 2M, ITV IPhase, ITV $_{\text {MinIP }}$ and ITV MIP $\left(\mathrm{cm}^{3}\right)$

\begin{tabular}{cccccc}
\hline Patient & ITV $_{\text {AllPhases }}$ & ITV $_{\mathbf{2 M}}$ & ITV $_{\mathbf{2 P h a s e}}$ & ITV $_{\mathbf{M i n I P}}$ & ITV $_{\mathbf{M I P}}$ \\
\hline 1 & 52.8 & 44.2 & 43.2 & 32.5 & 41.5 \\
2 & 50.9 & 48.8 & 47.1 & 43.7 & 43.6 \\
3 & 112.6 & 101.4 & 102.4 & 97.5 & 80.9 \\
4 & 100.1 & 94.8 & 91.2 & 70.9 & 94.5 \\
5 & 5.7 & 5.1 & 4.3 & 5.0 & 4.1 \\
6 & 5.0 & 4.7 & 4.1 & 4.6 & 2.9 \\
7 & 96.1 & 91.4 & 85.3 & 56.0 & 90.0 \\
8 & 6.8 & 6.5 & 5.9 & 6.5 & 5.0 \\
9 & 294.8 & 283.0 & 280.6 & 233.3 & 275.2 \\
10 & 569.3 & 549.6 & 514.6 & 390.3 & 528.7 \\
11 & 99.5 & 95.7 & 88.9 & 93.8 & 86.2 \\
12 & 40.3 & 38.9 & 37.2 & 38.8 & 30.1 \\
13 & 123.2 & 116.8 & 110.0 & 98.9 & 104.9 \\
14 & 1082.7 & 1041.1 & 1040.3 & 963.8 & 1013.6 \\
15 & 372.0 & 357.6 & 347.3 & 355.7 & 312.5 \\
Mean & 200.8 & 192.0 & 186.8 & 166.1 & 180.9 \\
SD & 290.4 & 280.0 & 277.0 & 252.0 & 272.0 \\
\hline
\end{tabular}


Table $4 \mathrm{MI}$ values for four ITVs based on ITV $2 \mathrm{M}$, ITV 2 Phase, ITV $_{\text {MinIP }}$ and ITV MIP $_{\text {relative to the reference ITV }}$ AllPhases

\begin{tabular}{ccccc}
\hline Patient & $\mathbf{I T V}_{\mathbf{2 M}}$ & $\mathbf{I T V}_{\mathbf{2 P h a s e}}$ & $\mathbf{I T V}_{\mathbf{M i n I}}$ & $\mathbf{I T V}_{\mathbf{M I P}}$ \\
\hline 1 & .83 & .82 & .61 & .78 \\
2 & .94 & .92 & .86 & .83 \\
3 & .89 & .91 & .86 & .72 \\
4 & .93 & .91 & .71 & .93 \\
5 & .89 & .75 & .87 & .73 \\
6 & .91 & .81 & .91 & .58 \\
7 & .94 & .89 & .58 & .93 \\
8 & .95 & .87 & .95 & .72 \\
9 & .94 & .95 & .79 & .92 \\
10 & .95 & .90 & .68 & .92 \\
11 & .95 & .89 & .94 & .86 \\
12 & .95 & .92 & .95 & .75 \\
13 & .93 & .89 & .80 & .84 \\
14 & .96 & .96 & .89 & .93 \\
15 & .96 & .94 & .95 & .84 \\
Mean & .93 & .89 & .82 & .82 \\
SD & .04 & .06 & .12 & .10 \\
\hline
\end{tabular}

We further analyze the tumor characteristics, which would impact MI.

1). $\mathrm{MI}$ and tumor volume: As lesion of $>5 \mathrm{~cm}$ is not a candidate for stereotactic body radiation therapy in our practice, the patients were split into two groups: $\leq$ $65.4 \mathrm{~cm}^{3}$ (equivalent to the volume of a sphere with 5 $\mathrm{cm}$ in diameter) vs. $>65.4 \mathrm{~cm}^{3}$. MIs of $\mathrm{ITV}_{2 \mathrm{M}}$ were 0.94 \pm 0.02 for the former and $0.92 \pm 0.04$ for the latter $(p=$ $0.260)$. Nevertheless, there was significant difference between tumor size and MIs of ITV $_{2 \text { Phase, }}$ MI being 0.92 \pm 0.03 for tumor of $\leq 65.4 \mathrm{~cm}^{3}$ and $0.85 \pm 0.06$ for tumor of $>65.4 \mathrm{~cm}^{3}(p=0.015)$. For $\mathrm{ITV}_{2 \mathrm{M}}$ as tumor volume increased MI did not change much with no correlation between them $(\mathrm{R}=0.364, p=0.182)$. However, for $\mathrm{ITV}_{2 \text { Phase, }}$ when tumor volume increased MI was significantly enhanced with positive correlation $(R=0.527$, $p=0.044$ ) (Figure 2).

2). MI and target motion three-dimensionally: It is recommended that for tumor motion of $>10 \mathrm{~mm}$, we need to reduce the movement by breath control devices, such as Active Breathing Coordinator or RPM gating system. The patients were divided into two groups: 3D vector of $\leq 10 \mathrm{~mm}$ vs. $>10 \mathrm{~mm}$. Mean MIs of $\mathrm{ITV}_{2 \mathrm{M}}$ were $0.94 \pm 0.01$ and $0.92 \pm 0.04(p=0.542)$, and mean of MIs of $\mathrm{ITV}_{2 \text { Phase }}, 0.88 \pm 0.04$ and $0.89 \pm 0.06(p=$ $0.756)$, respectively for the former and the latter. There was no significant correlation between the magnitude of target motion and MI.

3). MI and ratio of tumor vertical diameter over tumor motion magnitude in cranio-caudal direction: As shown in Figure 3, for $\mathrm{ITV}_{2 \mathrm{M}}$ when vertical diameter over tumor motion magnitude in cranio-caudal direction

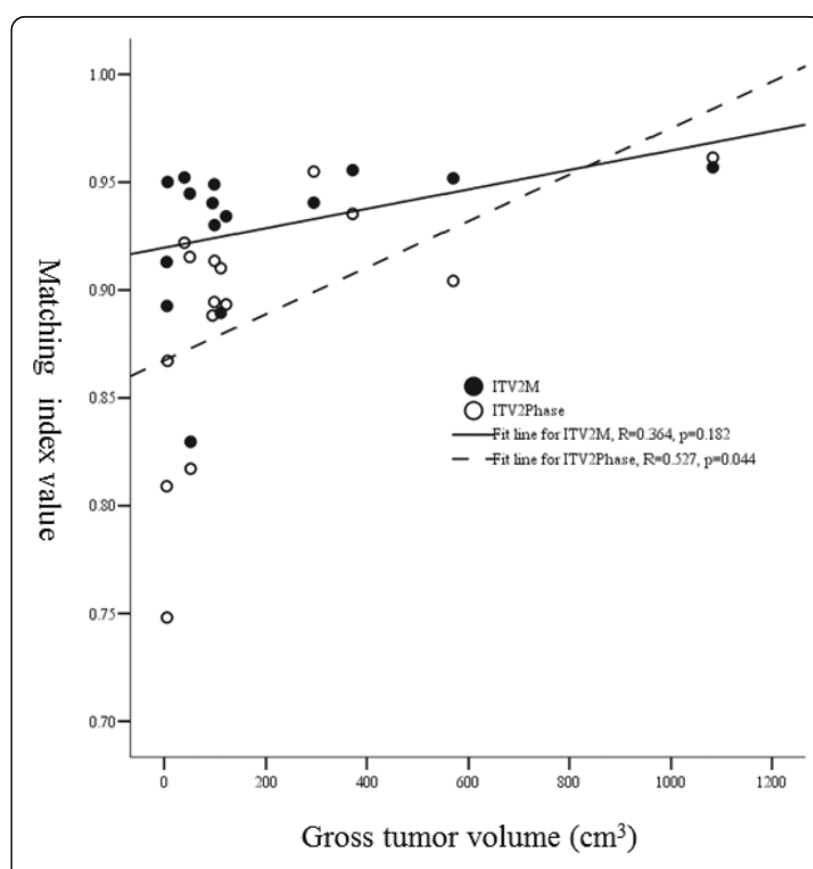

Figure 2 Relationship between gross tumor volume and MI values of $I T V_{2 M}$ and ITV 2 Phase.

increased MI was increased slightly, but with no significant correlation $(\mathrm{R}=0.352, p=0.198)$. However, for $\mathrm{ITV}_{2 \text { Phase }}$ there was a positive correlation between them $(\mathrm{R}=0.535, p=0.040)$.

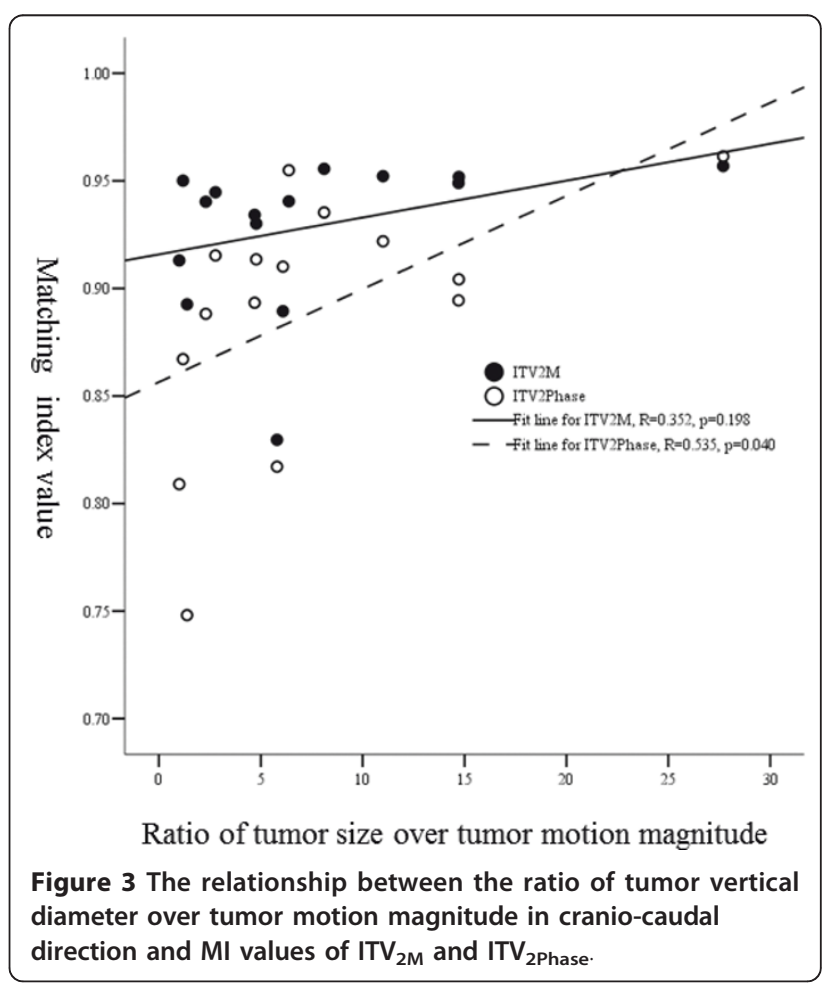


4). MI and tumor density: For the tumor of low density or mixed density, there was no significant difference in MIs between them for both ITV $_{2 \mathrm{M}}$ and ITV $\mathrm{IPhase}_{2}$, MIs of ITV $_{2 \mathrm{M}}$ being $0.93 \pm 0.02$ and $0.92 \pm 0.05$ ( $p=$ $0.676)$, and MIs of ITV $_{2 \text { Phase, }} 0.88 \pm 0.07$ and $0.90 \pm$ $0.05(p=0.702)$, respectively for low density tumor and the mixed. However, for low density tumor MI of ITVMinIP was better than that for mixed density tumor with MI of $0.90 \pm 0.05$ and $0.71 \pm 0.11(p=0.001)$, respectively.

We also noticed that for low density tumors, which located within liver parenchyma and were not closed to adjacent organs, such as $5^{\text {th }}, 6^{\text {th }}, 8^{\text {th }}$ and $12^{\text {th }}$ patient (Table 1), when using ITV MinIP mean MI was $0.92 \pm$ 0.04 , while using $\mathrm{ITV}_{2 \mathrm{M}}$ it was $0.93 \pm 0.03$ with no significant difference between $\operatorname{ITV}_{\text {MinIP }}$ and $\operatorname{ITV}_{2 \mathrm{M}}(p=$ 0.114).

(3). Proportion of $V_{\text {under }}$

Figure 4 illustrates the proportions of $V_{\text {under }}$ in 15

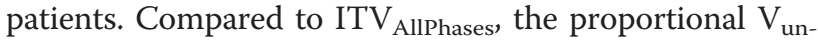
der of $\mathrm{ITV}_{2 \mathrm{M}}$ was the lowest $(0.07 \pm 0.04)$ with the maximum of 0.17 among ITV 2 Phase, ITV MinIP, ITV $_{\text {MIP }}$ and $\mathrm{ITV}_{2 \mathrm{M}}$. While proportional $\mathrm{V}_{\text {under }}$ of $\mathrm{ITV}_{2 \text { Phase }}$ was 0.11 \pm 0.06 with the maximum of 0.26 . The mean proportion of $\mathrm{V}_{\text {under }}$ for $\mathrm{ITV}_{2 \mathrm{M}}$ were significantly less than that for $\operatorname{ITV}_{2 \text { Phase }}(p=0.001)$. However, ITV MinIP $_{\text {and ITV }}$ MIP underestimated larger volumes, the proportions of $\mathrm{V}_{\mathrm{un}}$ der being $0.18 \pm 0.12$ and $0.18 \pm 0.11$, respectively.

The analyses of tumor characteristics, which would impact proportion of $\mathrm{V}_{\text {under }}$ were as follows.

1). Proportion of $V_{\text {under }}$ and tumor volume: There were no correlations between the diameter of GTV and the proportion of $V_{\text {under }}$ for $\mathrm{ITV}_{2 \mathrm{M}}$, no matter the

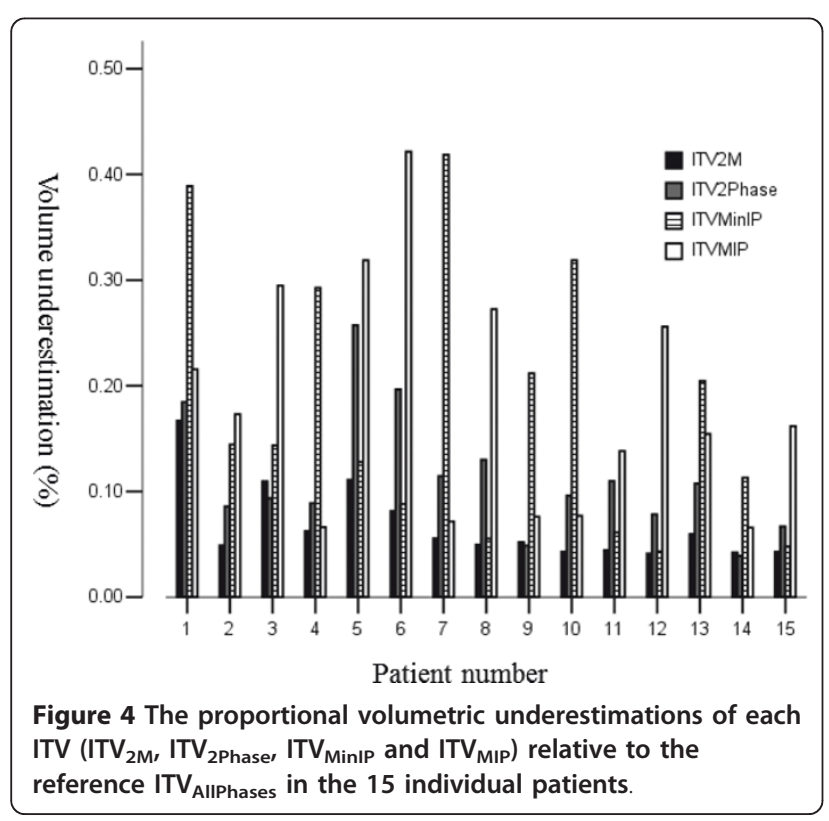

diameter over than or less than $5 \mathrm{~cm}$. The proportions of $\mathrm{V}_{\text {under }}$ were respectively $0.06 \pm 0.02$ and $0.08 \pm 0.05$ $(p=0.244)$. However, there was significant difference in proportion of $\mathrm{V}_{\text {under }}$ between tumor size of $\leq 5 \mathrm{~cm}$ and $>5 \mathrm{~cm}$ with proportions of ITV $_{2 \text { Phase }}$ being $0.08 \pm 0.03$ and $0.15 \pm 0.07(p=0.018)$, respectively. For $\mathrm{ITV}_{2 \mathrm{M}}$ as tumor size increased the proportions of $\mathrm{V}_{\text {under }}$ did not change significantly with no correlations between them $(\mathrm{R}=-0.340, p=0.215)$. In contrast, for $\mathrm{ITV}_{2 \text { Phase }}$ there was negative correlation between GTV volume and the proportion of $\mathrm{V}_{\text {under }}(\mathrm{R}=-0.528, p=0.043)$ (Figure 5).

2). Proportion of $V_{\text {under }}$ and target motion threedimensionally: There was no strong correlation between 3 victor tumor motion of $\leq 10 \mathrm{~mm}$ and $>10$ $\mathrm{mm}$, and the proportions of $\mathrm{V}_{\text {under }}$ were $0.06 \pm 0.01$ and $0.07 \pm 0.04(p=0.480)$ for $\mathrm{ITV}_{2 \mathrm{M}}$, and $0.12 \pm 0.04$ and $0.10 \pm 0.07(p=0.758)$ for ITV $_{\text {2phase }}$.

$3)$. Proportion of $V_{\text {under }}$ and ratio of tumor vertical diameter over tumor motion: For ITV $2 \mathrm{M}$ there was no strong correlation between them $(\mathrm{R}=-0.344, p=0.210)$. However, for $\mathrm{ITV}_{2 \text { phase }}$ as ratio of tumor vertical diameter over tumor motion increased the proportions of $\mathrm{V}_{\text {under }}$ decreased significantly $(\mathrm{R}=-0.523, p=0.040)$ (Figure 6).

4). Proportion of $V_{\text {under }}$ and tumor density: For both low density and mixed density tumors there was no significant difference in the underestimations, regardless ITV $2 \mathrm{M}$ or ITV 2 Phase, For ITV $\mathrm{ITM}_{2 \mathrm{M}}$ the proportions of $\mathrm{V}_{\text {under }}$ were $0.06 \pm 0.03$ and $0.07 \pm 0.05(p=0.723)$,

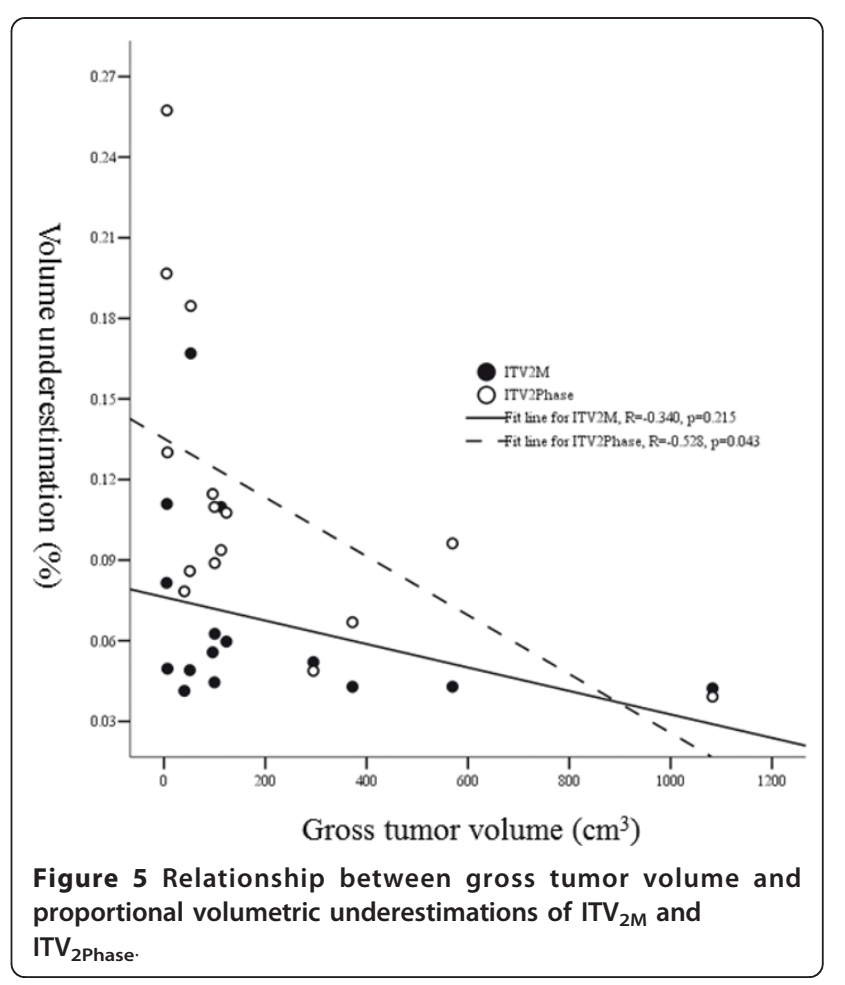




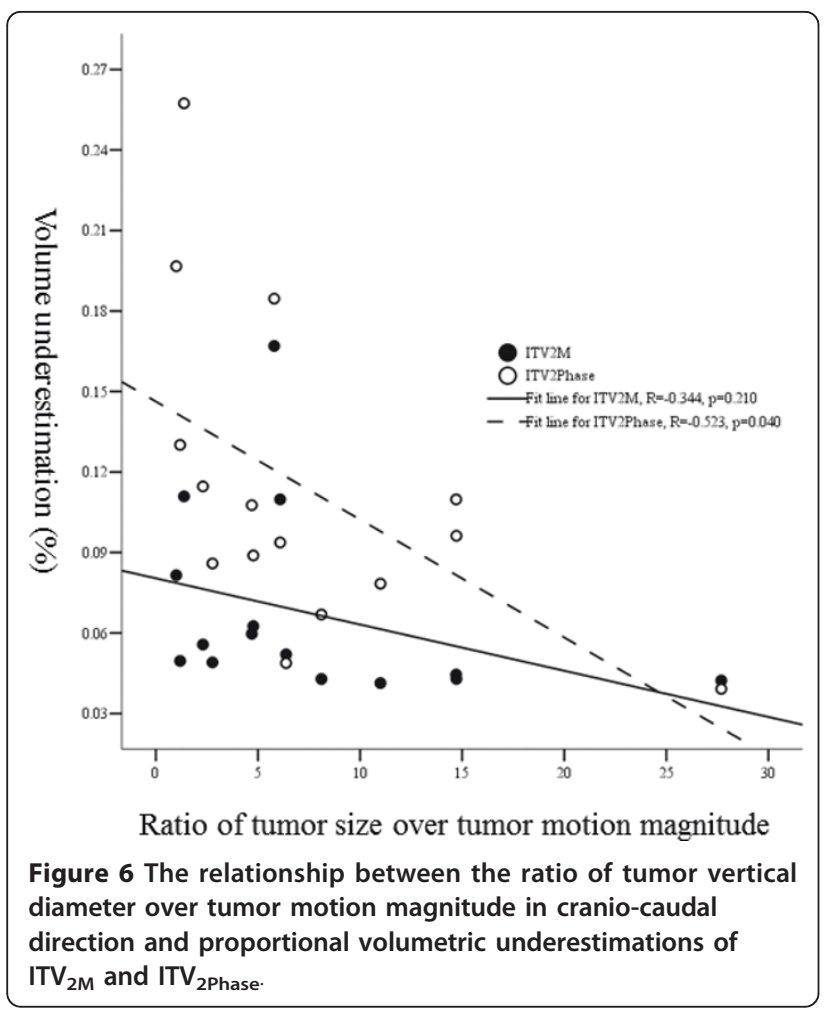

respectively for low density tumor and the mixed, and for $\mathrm{ITV}_{2 \text { Phase }}$ they were $0.12 \pm 0.07$ and $0.11 \pm 0.05(p=$ 0.680 ). However, when using $\mathrm{ITV}_{\text {MinIP }}$ the underestimated proportion was $0.10 \pm 0.06$ for 9 low density tumors, but it was $0.29 \pm 0.11$ for 6 mixed density tumors $(p=0.001)$.

As for MI in $5^{\text {th }}, 6^{\text {th }}, 8^{\text {th }}$ and $12^{\text {th }}$ patient, when ITVMinIP was used the mean proportion of $\mathrm{V}_{\text {under }}$ was 0.08 \pm 0.04 , while it was $0.07 \pm 0.03$ when $\mathrm{ITV}_{2 \mathrm{M}}$ was used $(p=0.094)$.

(4). $V_{\text {over }}$

Compared to ITV $\mathrm{V}_{\text {AllPhases }}$, the percentages of $\mathrm{V}_{\text {over }}$ were all less than $1 \%$ for ITV $_{2 \text { phase }}$, ITV $\mathrm{IVinIP}_{\text {, ITV }}$ MIP and $\mathrm{ITV}_{2 \mathrm{M}}$.

\section{Discussion}

MIP method as an image post-processing is based on more complex algorithms and can be used for generating three-dimensional vascular reconstructions $[14,15]$. In lung cancer, MIPs are believed to be a reliable tool to generate ITVs from 4D CT data sets [10], however, it is mandatory to modify each individual MIP to improve ITV delineation for tumors adjacent to the thoracic wall, mediastinum, heart, or diaphragm $[11,12]$. In the current study, we also had to verify ITVs contoured on MIP and MinIP CT by overlaying it on a movie loop displaying 4D CT data and then editing it, especially for those closed to adjacent organs. Mancosu had recently proposed a semiautomatic technique, which allowed for inclusion of the residual part of ITV covered by liver and spleen cupola when using MIP algorithm. It was validated on phantom and selected patients, which revealed this possibility when lesion located near liver and spleen cupola by performing only the contours on MIP series [16]. Thus, the dedicated software needs to be developed to exclude diaphragm and chest wall in some breathing phases using 4D CT for better tumor MIP/MinIP images.

Theoretically, for tumors with homogeneous hyperdensity or hypodensity compared to the surrounding normal liver, MIP or MinIP projections should accordingly reflect the tumor trajectory across all time-resolved data sets. In patients when the lesions were homogenous low CT density, located intrahepatic, not adjacent to perihepatic organs and also small size $\left(5^{\text {th }}, 6^{\text {th }}, 8^{\text {th }}\right.$ and $12^{\text {th }}$ patient), using MinIP was also an appropriate tool with good MI of $0.92 \pm 0.04$ and low proportion of $\mathrm{V}_{\text {un- }}$ der of $0.08 \pm 0.04$. Thus, ITV MinIP method can be used for fast contouring of liver tumor with homogeneous low CT density including respiratory motion.

However, a number of liver cancers present inhomogeneous density, results from this study showed combined MIP and MinIP fit excellently in this situation. In current study we compared MIs and proportions of $V_{u n-}$ der resulting from ITV $_{2 \text { Phase }}, \mathrm{ITV}_{\text {MinIP }}$, ITV $\mathrm{IIP}_{\text {MI }}$ and $\mathrm{ITV}_{2 \mathrm{M}}$ contoured by 4 approaches, and found that the closest to ITV $\mathrm{IIllPhases}_{\text {was }}$ the combined one $\left(\mathrm{ITV}_{2 \mathrm{M}}\right)$ of $I_{T V} V_{\text {MinIP }}$ and ITV $V_{\text {MIP }}$, which were contoured on MinIP and MIP series of 4D CT set because it resulted in the highest $\mathrm{MI}$ and lowest proportion of $\mathrm{V}_{\text {under }}$. Moreover, the size of tumor and the ratio of tumor vertical diameter over cranio-caudal movement did not have influence on MI or proportion of $V_{\text {under }}$ when using $I_{T V} V_{2 M}$. In other words, no matter how big the tumor was, and the tumor vertical diameter over cranio-caudal movement was small or big, the tool of ITV $_{2 M}$ could always result in the best outcome.

For moving target it was also a practice to sum 2 GTVs to generate ITV, one contoured on CT image set acquired after end-inhale and holding breath and the other contoured on CT acquired after end-exhale and holding breath when 4D CT was not available. The similar method was also used for 4D CT, i.e., to contour only two extreme phases at end-inhalation and endexhalation. However, possible hysteresis effects would be neglected as occurred in lung cancer $[17,18]$. Seppenwoolde and colleagues [18] reported that when the tumor was small and had a large range of motion, the separation between the positions of the images of inspiration and expiration phases was relatively obvious and the information of the intermediate breathing might not be comprehensive. Besides, the combined images of 
the two time phases might omit the lag of the tumor. The phenomenon was caused by the time difference among the document recorded by the computer, the transition of respiratory cycle and the transition between inspiration and expiration in a respiratory cycle. $\mathrm{Xi}$ [9] reported the feasibility of using limited $4 \mathrm{D} C \mathrm{CT}$ images for treatment planning for liver radiotherapy. As recognized by the authors, deriving ITV by two extreme phases was reasonably safe only for low and medium tumor motion amplitude $(<1.6 \mathrm{~cm})$. The tumor motion in cranio-caudal direction between Xi's study and ours' were comparable, but the tumor size of our data $(152.20$ $\left.\mathrm{cm}^{3} \pm 242.85 \mathrm{~cm}^{3}\right)$ was more diverse than Xi's $(70.36$ $\left.\mathrm{cm}^{3} \pm 66.23 \mathrm{~cm}^{3}\right)$. Xi did not investigate the influence of tumor size on ITV determination using 4D CT data. Our study did find a smaller volume of $\operatorname{ITV}_{\text {2Phase }}(186.8$ $\left.\mathrm{cm}^{3}\right)$ than that of ITV cant difference $(p=0.004)$. And also we found that MI and proportion of $\mathrm{V}_{\text {under }}$ were influenced by the tumor volume and the ratio of tumor size over tumor motion magnitude significantly. Whereas, $\mathrm{ITV}_{2 \mathrm{M}}$ was the closest to $\mathrm{ITV}_{\mathrm{AllPh}}$, and $\mathrm{MI}$ and proportion of $\mathrm{V}_{\text {under }}$ were not influenced by tumor volume and the ratio of tumor size over tumor motion magnitude when using tool of $\mathrm{ITV}_{2 \mathrm{M}}$.

\section{Conclusion}

To reduce the workload of contouring multiple GTVs in 4D CT data sets, contouring only two extreme phases is appropriate only when tumor volume is big and tumor motion magnitude is relatively small. For hepatic malignancies with inhomogeneous density we found that the method of using $\mathrm{ITV}_{2 \mathrm{M}}$ was a more reliable and appropriate tool for generating ITVs from 4D CT data sets, compared to the others.

\section{Acknowledgements}

This study was funded by National Science Foundation of China (Grant No. 30800279)

\section{Authors' contributions}

ZJD and JGL designed the study. LJ, WJZ and ZJD did the study and wrote the manuscript. JGL was responsible for manuscript revision and submission. WJZ and XZY were involved in 4D CT simulation and data analysis. All authors read and approved the final version of the manuscript.

\section{Competing interests}

The authors declare that they have no competing interests.

Received: 14 October 2011 Accepted: 30 January 2012 Published: 30 January 2012

\section{References}

1. Swaminath A, Dawson LA: Emerging role of radiotherapy in the management of liver metastases. Cancer J 2010, 16:150-155.

2. Ren ZG, Zhao JD, Gu K, Chen Z, Lin JH, Xu ZY, Hu WG, Zhou ZH, Liu LM, Jiang GL: Three-dimensional conformal radiation therapy and intensitymodulated radiation therapy combined with transcatheter arterial chemoembolization for locally advanced hepatocellular carcinoma: an irradiation dose escalation study. Int I Radiat Oncol Biol Phys 2011, 79:496-502.

3. Langen KM, Jones DT: Organ motion and its management. Int I Radiat Oncol Biol Phys 2001, 50:265-278.

4. Vedam SS, Keall PJ, Kini VR, Mostafavi H, Shukla HP, Mohan R: Acquiring a four-dimensional computed tomography dataset using an external respiratory signal. Phys Med Biol 2003, 48:45-62.

5. Keall PJ, Starkschall G, Shukla H, Forster KM, Ortiz V, Stevens CW, Vedam SS, George R, Guerrero T, Mohan R: Acquiring 4D thoracic CT scans using a multislice helical method. Phys Med Biol 2004, 49:2053-2067.

6. Liu HH, Balter P, Tutt T, Choi B, Zhang J, Wang C, Chi M, Luo D, Pan T, Hunjan S, Starkschall G, Rosen I, Prado K, Liao Z, Chang J, Komaki R, Cox JD, Mohan R, Dong L: Assessing respiration-induced tumor motion and internal target volume using four-dimensional computed tomography for radiotherapy of lung cancer. Int J Radiat Oncol Biol Phys 2007, 68:531-540.

7. Jin JY, Ailouni $M$, Chen $Q$, Yin FF, Movsas B: A technique of using gated$\mathrm{CT}$ images to determine internal target volume (ITV) for fractionated stereotactic lung radiotherapy. Radiother Oncol 2006, 78:177-184.

8. Guckenberger M, Sweeney RA, Wilbert J, Krieger T, Richter A, Baier K, Mueller G, Sauer O, Flentje M: Image-guided radiotherapy for liver cancer using respiratory-correlated computed tomography and cone-beam computed tomography. Int J Radiat Oncol Biol Phys 2008, 71:297-304.

9. Xi M, Liu MZ, Zhang L, Li QQ, Huang XY, Liu H, Hu YH: How many sets of $4 D C T$ images are sufficient to determine internal target volume for liver radiotherapy. Radiother Oncol 2009, 92:255-259.

10. Underberg RW, Lagerwaard FJ, Slotman BJ, Cuijpers JP, Senan S: Use of maximum intensity projections (MIP) for target volume generation in 4DCT scans for lung cancer. Int I Radiat Oncol Biol Phys 2005, 63:253-260.

11. Ezhil M, Vedam S, Balter P, Choi B, Mirkovic D, Starkschall G, Chang JY: Determination of patient-specific internal gross tumor volumes for lung cancer using four-dimensional computed tomography. Radiat Oncol 2009, 4:4.

12. Rietzel E, Liu AK, Chen GT, Choi NC: Maximum-intensity volumes for fast contouring of lung tumors including respiratory motion in 4DCT planning. Int J Radiat Oncol Biol Phys 2008, 71:1245-1252.

13. Beddar AS, Briere TM, Balter P, Pan T, Tolani N, Ng C, Szklaruk J, Krishnan S: $4 \mathrm{D}-\mathrm{CT}$ imaging with synchronized intravenous contrast injection to improve delineation of liver tumors for treatment planning. Radiother Oncol 2008, 87:445-448.

14. Sato Y, Shiraga N, Nakajima S, Tamura S, Kikinis R: Local maximum intensity projection (LMIP): a new rendering method for vascular visualization. J Comput Assist Tomogr 1998, 22:912-917.

15. Lin W, Haacke EM, Masaryk TJ, Smith AS: Automated local maximum intensity projection with three-dimensional vessel tracking. J Magn Reson Imaging 1992, 2:519-526.

16. Mancosu P, Sghedoni R, Bettinardi V, Aquilina MA, Navarria P, Cattaneo GM, Di MN, Cozzi L, Scorsetti M: Semiautomatic technique for defining the internal gross tumor volume of lung tumors close to liver/spleen cupola by 4D-CT. Med Phys 2010, 37:4572-4576.

17. Mageras GS, Pevsner A, Yorke ED, Rosenzweig KE, Ford EC, Hertanto A, Larson SM, Lovelock DM, Erdi YE, Nehmeh SA, Humm JL, Ling CC: Measurement of lung tumor motion using respiration-correlated CT. Int J Radiat Oncol Biol Phys 2004, 60:933-941.

18. Seppenwoolde $Y$, Shirato H, Kitamura K, Shimizu S, van HM, Lebesque JV, Miyasaka K: Precise and real-time measurement of 3D tumor motion in lung due to breathing and heartbeat, measured during radiotherapy. Int J Radiat Oncol Biol Phys 2002, 53:822-834.

doi:10.1186/1748-717X-7-11

Cite this article as: Liu et al:: Use of combined maximum and minimum intensity projections to determine internal target volume in 4dimensional CT scans for hepatic malignancies. Radiation Oncology 2012 7:11. 